\title{
Management of sepsis in resource poor countries: cutting your coat according to your cloth
}

\section{Gentle S Shrestha}

Low and middle-income countries (LMICs) bear the largest part of the global burden of sepsis. ${ }^{1}$ In these resource poor countries, outcome of patients with sepsis is poorer and the mortality is higher, when compared to developed nations. ${ }^{2}$ Current international guidelines for management of sepsis and septic shock is largely based on studies and research from resource rich settings. ${ }^{3}$ Applicability of such guidelines in resource poor settings can be questionable due to difference in availability of trained health care workers, laboratory support, equipments, infrastructure and logistics. ${ }^{4}$ Extrapolation of the recommendations may, in some instances, be harmful. In African children with severe infection, administration of a fluid bolus (as recommended by international guidelines) was associated with a higher mortality than restrictive fluid management. ${ }^{5}$ Similarly, early initiation of enteral feeding in non-intubated patients with cerebral malaria may increase mortality in resource-poor settings. ${ }^{6}$ Recent definition considers sepsis as a life-threatening organ dysfunction caused by a dysregulated host response to infection. ${ }^{7}$ Etiology of sepsis in resource poor settings is different than those in developed countries. Malaria, dengue, typhus, leptospirosis and viral hemorrhagic fever contribute significantly to the cause of sepsis. Pathophysiology of sepsis due to these etiologies varies from the bacterial sepsis. Similarly, some principles of management would differ, especially those related to fluid resuscitation and fluid management. ${ }^{8}$ For detection of organ dysfunction due to sepsis, the recent definition suggests the use of Sequential Organ Failure Assessment (SOFA) score. An increment of 2 or more points is considered to indicate organ dysfunction. A new bedside clinical score termed quick SOFA (qSOFA) has been suggested to identify the patients with infection, who are likely to have poor outcome. ${ }^{7}$ In resource poor settings, effective application of the new definition, and thus calculation of SOFA score, can be challenging due to lack of resources and trained clinicians. ${ }^{9}$ Recent recommendations suggest the use of qSOFA to diagnose sepsis in resource-limited settings. ${ }^{10}$ However, when compared to SOFA, qSOFA may have limited utility to predict mortality in patients with sepsis in ICU. ${ }^{11}$ Early sepsis recognition is one of the key elements that can improve the patient outcome. ${ }^{12}$ The tool or scoring system used for diagnosis of sepsis should be validated in resource poor settings and should have simple and easily obtainable values or parameters at bedside. ${ }^{9,13,14}$ Besides early detection, initial focused resuscitation, together with proper post-resuscitation monitoring and reassessment can improve outcome in patients with sepsis in resource limited settings. ${ }^{12}$ Knowledge and understanding of sepsis if often sub-optimal in the first line health care workers from resource limited settings. ${ }^{15}$ Training of medical practitioners about recognition of sepsis, resuscitation and monitoring can improve the care of these patients. ${ }^{12}$
Introduction of early goal-directed therapy (EGDT) for treatment of sepsis and septic shock revolutionized the management of sepsis. ${ }^{16}$ However, subsequent multicentric studies showed that EGDT did not confer better results than usual care and was associated with higher utilization of resources and higher cost. Of note, all three multicentric trials after EGDT were conducted in resource rich settings. Early recognition of sepsis, early fluid resuscitation and administration of antibiotics were performed in all patients as the part of usual care. These findings may not be generalized to LMICs where the trained health care workers are limited and mortality of sepsis remains high..$^{2,15,17}$ In resource limited settings with scarcity of trained personnel, use of protocols and checklists would depend less on highly specialized knowledge and may improve outcome. ${ }^{18-20}$

Recommendations for management of sepsis in resource poor setting should consider availability of resources, feasibility, affordability and safety; similar to the concept of cutting the coat according to the cloth. ${ }^{4}$ Early diagnosis and appropriate management of non-bacterial etiology of sepsis should be considered. ${ }^{8}$ Empirical antibiotic selection should be based on local disease epidemiology and antibiotic susceptibility patterns. Due to lack of antimicrobial stewardship programs, multidrug resistant organisms causing sepsis are quite common in resource poor settings. ${ }^{21}$ As the ICU capacities and level of care might vary widely even in the resource limited settings, recommendations for management based on availability of diagnostic facilities and training of medical personnel may be reasonable.,22,23 Easily available bedside tools like point-of-care ultrasonography can be a valuable adjunct to facilitate management of these patients. ${ }^{24,25}$ There is a dearth of research in resource-poor settings in the field of sepsis management. ${ }^{26}$ Future research should focus on need assessment, prognostic scoring and cost-effectiveness evaluation. ${ }^{18}$ This largely unexplored field of critical care medicine should be the focus for future research, which would potentially generate good quality evidences and thus may improve the outcome of patients with sepsis in resource poor settings. ${ }^{26}$

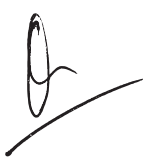

Dr. Gentle S Shrestha

MD, FACC, EDIC, FCCP

Intensivist \& Anesthesiologist

Tribhuvan University Teaching Hospital

Maharajgunj, Kathmandu, Nepal

Email: gentlesunder@hotmail.com

Phone: +977-9841248584 


\section{References:}

1. Cheng AC, West TE, Limmathurotsakul D, Peacock SJ. Strategies to reduce mortality for bacterial sepsis in adults in developing countries. PLoS Med 2008;5:e175.

2. Vincent JL, Marshall JC, Namendys-Silva SA, Francois B, Martin-Loeches I, Lipman J, et al. Assessment of the worldwide burden of critical illness: the intensive care over nations (ICON) audit. Lancet Respir Med 2014;2:380-6.

3. Rhodes A, Evans LE, Alhazzani W, Levy MM, Antonelli M, Ferrer $\mathrm{R}$, et al. Surviving sepsis campaign: International guidelines for management of sepsis and septic shock: 2016. Intensive Care Med 2017;43:304-77.

4. Mer M, Schultz MJ, Adhikari NK; European Society of Intensive Care Medicine (ESICM) Global Intensive Care Working Group and the Mahidol-Oxford Research Unit (MORU), Bangkok, Thailand. Core elements of general supportive care for patients with sepsis and septic shock in resource-limited settings. Intensive Care Med 2017 Jun 15. doi: 10.1007/s00134-017-4831-z.

5. Maitland K, Kiguli S, Opoka RO, Engoru C, Olupot-Olupot P, Akech SO, et al. Mortality after fluid bolus in African children with severe infection. N Engl J Med 2011;364:2483-95.

6. Maude RJ, Hoque G, Hasan MU, Sayeed A, Akter S, Samad R, et al. Timing of enteral feeding in cerebral malaria in resource-poor settings: a randomized trial. PLoS One 2011;6:e27273.

7. Singer M, Deutschman CS, Seymour CW, Shankar-Hari M, Annane D, Bauer $\mathrm{M}$, et al. The third international consensus definitions for sepsis and septic shock (Sepsis-3). JAMA 2016;315:801-10

8. Dondorp AM, Hoang MNT, Mer M; Sepsis in Resource-Limited Settings-Expert Consensus Recommendations Group of the European Society of Intensive Care Medicine (ESICM) and the Mahidol-Oxford Research Unit (MORU) in Bangkok, Thailand. Recommendations for the management of severe malaria and severe dengue in resource-limited settings. Intensive Care Med 2016 Nov 5. doi: 10.1007/s00134-016-4602-2.

9. Shrestha GS. Composition of the sepsis definition task force. JAMA 2016;316:459-60.

10. Kwizera A, Festic E, Dunser MW. What's new in sepsis recognition in resource-limited settings? Intensive Care Med 2016;42:2030-3.

11. Raith EP, Udy AA, Bailey M, McGloughlin S, Maclsaac C, Bellomo R, et al. Prognostic accuracy of the SOFA score, SIRS criteria, and qSOFA score for in-hospital mortality among adults with suspected infection admitted to the intensive care unit. JAMA 2017;317:290-300.

12. Papali A, McCurdy MT, Calvello EJ. A "three delays" model for severe sepsis in resource-limited countries. J Crit Care 2015;30:861.e9-14.

13. Haniffa R, Pubudu De Silva A, Weerathunga P, Mukaka M, Athapattu P, Munasinghe S, et al. Applicability of the APACHE II model to a lower middle income country. J Crit Care 2017 Jul 13;42:178-183. doi: 10.1016/j.jcrc.2017.07.022.
14. Grissom CK, Brown SM, Kuttler KG, Boltax JP, Jones J, Jephson $\mathrm{AR}$, et al. A modified sequential organ failure assessment score for critical care triage. Disaster Med Public Health Prep 2010;4:277-84.

15. Shrestha GS, Parajuli BP, Banstola A, Upadhyay B, Acharya SP, Bajracharya $\mathrm{T}$. Understanding of severe sepsis and septic shock among emergency department and intensive care unit medical officers in a developing country Nepal: A survey study. BJHS 2016;1:48-51.

16. Rivers E, Nguyen B, Havstad S, Ressler J, Muzzin A, Knoblich B, et al. Early goal-directed therapy in the treatment of severe sepsis and septic shock. N Engl J Med 2001;345:1368-77.

17. Eaton TL, Keener C, Landis K, Stapleton DK, Weissfeld LA, Willochell M, et al. Early, goal-directed therapy for septic shock A patient-level meta-analysis. N Engl J Med 2017;376:2223-34.

18. Riviello ED, Letchford S, Achieng L, Newton MW. Critical care in resource-poor settings: lessons learned and future directions. Crit Care Med 2011;39:860-7.

19. Levy MM, Dellinger RP, Townsend SR, Linde-Zwirble WT, Marshall JC, Bion J, et al. The surviving sepsis campaign: results of an international guideline-based performance improvement program targeting severe sepsis. Intensive Care Med 2010;36:222-31.

20. Phua J, Koh Y, Du B, Tang Y Q, Divatia JV, Tan CC, et al. Management of severe sepsis in patients admitted to Asian intensive care units: prospective cohort study. BMJ 2011;342:d3245

21. Dondorp AM, Iyer SS, Schultz MJ. Critical care in resource-restricted settings. JAMA 2016;315:753-4.

22. Dunser MW, Festic E, Dondorp A, Kissoon N, Ganbat T, Kwizera $A$, et al. Recommendations for sepsis management in resource-limited settings. Intensive Care Med 2012;38:557-74.

23. Hashmi M, Khan FH, Zubairi AB, Sultan ST, Haider S, Aftab S, et al. Developing local guidelines for management of sepsis in adults: Sepsis Guidelines for Pakistan (SGP). Anaesthesia Pain Intensive Care 2015;19:196-208.

24. Lictenstein DA. Point-of-care ultrasound: Infection control in the intensive care unit. Crit Care Med 2007;35:S262-7.

25. Mayo P, Arntfield R, Balik M, Kory P, Mathis G, Schmidt G, et al. The ICM research agenda on critical care ultrasonography. Intensive Care Med 2017 Mar 7. doi: 10.1007/s00134-017-4734-z.

26. Schultz MJ, Dunser MW, Dondorp AM, Adhikari NK, Iyer S, Kwisera A, et al. Current challenges in the management of sepsis in ICUs in resource-poor settings and suggestions for the future. Intensive Care Med 2017;43:612-24. 